\title{
Do You Believe in Magic?
}

\section{Exploring the Conceptualization of}

\section{Augmented Reality and its Implication:}

for the User in the Field of Library and

Information Science

\section{Elizabeth Zak}

\begin{abstract}
Augmented reality (AR) technology has implications for the ways that the field of library and information science (LIS) serves users and organizes information. Through content analysis, the author examined how AR is conceptualized within a sample of LIS literature from the Library, Information Science and Technology Abstracts (LISTA) database and Google Blogs postings. The author also examined whether Radical Change Theory (RCT) and the digital-age principles of interactivity, connectivity, and access are present in the discussion of this technology. The analysis of data led to the identification of 14 categories comprising 132 total codes across sources within the data set. The analysis indicates that the conceptualization of AR, while inconsistent, suggests expectations that the technology will enhance the user experience. This can lead to future examinations of user behavior, response, and observation of technologies like AR.
\end{abstract}

\section{INTRODUCTION}

It seems an understatement to say digital technology is changing quickly. Cell phones are like small computers in our pockets; we have access to far greater computing resources in "the cloud" than we did just five years ago, and computers are processing at speeds once only a fantasy. This digital revolution includes the continued development of augmented reality (AR) applications. At its simplest, AR is a blending of the physical environment with digital elements.

As with many of the latest technologies, the development of AR is interdisciplinary. Professionals in the fields of computer science, psychology, and philosophy seem to direct the discussion on the development and application of AR technology, as evidenced by the volume of literature when searching these subject databases for articles pertaining to AR. The field of library and information science (LIS) seems largely absent from the conversation.

While elements of AR, such as global positioning systems (GPS), quick response (QR) codes, and virtual reality are not uncommon in LIS literature, rarely are these topics defined as AR.

Information theory, information behavior, knowledge management, information architecture, and digital literacy (to name only a few) are key areas of study within LIS, which can be central in

Elizabeth Zak (ezak@dom.edu), is adjunct instructor at Dominican University, River Forest, Illinois. 
developing and exploring AR.

The focus on and the definitions of the user within LIS provide a much different perspective on the human aspect of engaging with digital information than is found within computer science.

Literature on human-computer interaction focuses more on the user as a piece of the system, with a shift only recently toward acknowledging this misdirected focus. $1,2,3,4,5,6,7,8$ Libraries and information agencies have the tools and skills-with regard to user interaction with and use of information - to help answer questions relating to how the conceptualization of a technology like AR influences the use of the technology.

\section{Augmented Reality (AR) Defined}

What is AR, really? Ronald Azuma, a pioneer and innovator in the research and creation of AR applications, describes AR as a supplement to reality. ${ }^{9}$ It combines the real and the virtual, aligning the virtual with the real environment. ${ }^{10} \mathrm{AR}$ is part of a mixed reality continuum, and "the technology depends on our ability to make coherent space from sensory information."11 This coherent space is dependent on several variables, one of which is AR's real-time interactivity. AR applications cannot experience any delays in response time; if the real and virtual are misaligned, it impedes the sense of reality. AR needs to happen at the same speed as real life-virtual actions coinciding with human actions, and variable across users.

Some also view AR as a new media experience, adding to the growing list of digital literacies. "While the pure technology provides a set of features that can be exploited, the features of the new technology will develop into one or more particular forms within a particular historical and cultural setting." 12 This includes "remediating" existing media, such as film or stage productions, with AR components.

As a result, $\mathrm{AR}$ is contextual and reliant on each personal experience, but it also borrows from earlier forms of media within those contexts and experiences. For this reason, it is important to examine just how those within LIS are constructing AR as a concept. The rapid pace at which AR is evolving and gaining in popularity suggests those within the field of LIS will need to be aware of new applications for the technology as more and more users may come to expect access to and knowledge of this technology.

Much of the literature also references AR as being an enhancement. But what, exactly, is AR enhancing? The answer includes our senses and perceptions, ${ }^{13}$ software, ${ }^{14}$ our emotions and feelings, ${ }^{15}$ and question-answering programs. ${ }^{16}$ Authors use the term enhancement with no explanation of how it is defined in each piece of literature. Some assume more is always better. Missing is the voice of the user or consumer, whom authors refer to as a subject or wearer. The irony is many of these users are the ones creating, building, and populating these AR worlds. I propose the field of LIS is in a prime position to address the missing piece of the research and discourse of AR. 
Many of the technological enhancements authors describe in the AR literature connect to the development of knowledge, one of the main goals of computing. ${ }^{17}$ There are a variety of settings in which some expect AR to create new routes to knowledge. Within a library setting, AR can improve library instruction, ${ }^{18}$ provide information retrieval about shelved books through recognition applications, ${ }^{19}$ reconstruct and restore artifacts, ${ }^{20}$ and deliver services at point of need through QR codes. ${ }^{21}$ Others view AR as a technological breakthrough with extreme potential in medical fields, such as non-invasive surgical visualization, which can display the organs through sensors placed on the body, helping medical practitioners and students to understand internal body functions. ${ }^{22}$

$\mathrm{AR}$ is also said to perform some of its "enhancements" in the classroom. ${ }^{23}$ Augmented books are growing in number and are expected to enhance collaboration and interactivity between students. Some allow more than one person to explore the same content at the same time or outside of the classroom through mobile technology; others give students the ability to rotate, tilt, and manipulate viewing angles of various objects. ${ }^{24}$

AR technology within art education is said to have a positive impact on student motivation. ${ }^{25}$ In a 2010 study, reference librarians at the University of Manitoba were given smartphones and asked to create innovative projects. What they came up with resulted in a public art project using social networks, GPS software, and AR technology that allowed users to interact with the art pieces through QR codes. ${ }^{26}$ Again and again, interactivity, connectivity, and mobility of AR applications are highlighted as efficient and motivating factors in education and learning. ${ }^{27,28,29,30}$

Organizations are also testing AR applications for general public use. Museums and galleries contain AR virtual displays of artifacts and historic scenes, personalizing interactive experiences and providing multiple perspectives of events and artifacts. ${ }^{31}$ The Natural History Museum in London, for example, created the Attenborough Studio in 2009 for live events and the viewing of AR enhanced films. ${ }^{32}$ AR tours are also offered on historic places and spaces. Augmented reality is already in use as a tour guide application, ${ }^{33}$ to supplement paper maps, ${ }^{34}$ and even to reconstruct damaged historic sites. ${ }^{35}$ AR is essentially a mutable form of displaying what are typically static objects and ideas.

The use of AR is integrative. It can saturate real landscapes, places, and spaces with virtual characteristics; it can add to or hide objects in the environment. ${ }^{36}$ Manipulation of the environment promotes "immersive experiences," 37 multifaceted for different people interacting with AR. ${ }^{38}$ Virtual experiences are expected to enhance the real-life experiences of the user. Spaces can become layered, or scaffold, not only through depth perception or AR software, but also through the user's contextual life experiences. ${ }^{39}$

With growing widespread use, it is imperative for those in the field of LIS to understand this technology and how it is used. How will these applications be archived? Will institutions and organizations collaborate with users in creating these applications? Will users expect librarians and other knowledge workers to help them understand and use the technology? Will libraries and 
other institutions use the technology, and if so, in what capacity? These are just some of the questions LIS professionals should be asking to ensure they are meeting user needs in relation to technology and the access of information through technology. This study provides a base for considering these questions, and the effects of AR, by situating the concept and expectations of AR within the field and aligning the conceptualization with Radical Change Theory.

\section{The User Within AR and LIS}

The use of AR can bring with it an altering of emotional and psychological experiences. Pederson argues AR applications should be "human-centric". ${ }^{40}$ Because human beings "instrumentalize" technology such as AR, the technology itself should accommodate the human needs for AR tools. ${ }^{41}$ For AR applications to be successful, they must display the human characteristics encompassing reactions to one another and the environment. ${ }^{42}$ Applications blurring the lines between the real and the virtual, and engaging the person in ways that play on perception, are capable of changing the real-life perceptions and expectations of the user. AR can be either a form of escapism for brief moments or an escape from what we know of as real-life for good. ${ }^{43}$

What much of the research assumes is the desire for AR applications. Lacking is surveys of user desire for AR, or examination of potential negative consequences. A user-focus is central to LIS and the values of librarianship. Within all these potential uses, what is not being discussed is how creators of AR applications organize, categorize and choose the information contained within these applications. Much of the discussion surrounding the implications of AR use is left to those in fields of philosophy and psychology, dealing in abstraction. The research and marketing of AR applications promote passive acceptance of AR technologies. ${ }^{44}$ There comes a point when AR researchers must ask, to what extent are potential users aware of and desirous of AR applications?

The notion of people as users is quite similar to the contextualization of human as subject in this scientific literature, different from the notion of user in LIS. In computer-science literature, users are those reacting to AR and providing AR researchers with content for AR modification as evaluators of the technology. Within computer-science literature, there is much talk of the user's satisfaction with tested AR applications; 45 there also much talk of the user's position within the AR frame/environment.46 Similar is the discussion of the user and the physical space of the AR application, and how the user responds to the AR functions. ${ }^{47}$ User and subject are terms used interchangeably in the scientific literature. These terms are largely undefined, indicating little regard for the role of the human outside of objectification as a tool working in the AR environment.

Within the field of LIS, the notion of the user takes on different characteristics: users are clearly patrons, human beings, for which LIS provides a service. Kuhlthau focuses on user-centric treatment of information services with her Information Search Process model. ${ }^{48}$ Chatman's theories of Information Poverty and Life in the Round both center on the information-seeking behaviors of ordinary people with everyday needs. ${ }^{49}$ 
Library anxiety, as developed by Mellon, pivots on the emotions and psychological responses of information-seekers, or users. ${ }^{50}$ There are many more theories and models demonstrating this user-centric focus in LIS. Case points to Dervin's 1976 article "Strategies for Dealing with Human Information Needs: Information or Communication?" as an exemplar of the shift in thinking about the role and needs of the user in LIS. ${ }^{51}$ Dervin pointed to assumptions in research on informationseeking, such as more information as better, and relevant information existing for every need. It is important to note whether there are assumptions now being made in LIS literature with regard to user interaction with AR and how best to understand user-centered design of AR applications.

Bowler et al. define user-centered design as "[reflecting] the user, typically from a cognitive, affective or behavioral point of view, as well as the social, organizational, and cultural contexts in which users function." ${ }^{52}$ These points of view - the cognitive, social, behavioral, and the like-all synchronize within AR applications. Bowler et al. state, "With the increased use of digital, networked information tools in daily practice and the emergence of the digital library and archive, it is impossible to separate the service from the system. In this context, understanding the user becomes more critical than ever." 53 With the advent of AR and its dependence on user interaction, it is imperative to continue to address the role of the user.

0'Brien and Toms further the discussion by trying to define user engagement with technology. The authors define engagement as a process, composed of three states: a point of engagement, a period of engagement and then finally disengagement. ${ }^{44}$ Attention to user needs and behavior as an individualized process is evident across LIS literature. Shu suggests user engagement in website design as a means to strengthening user relationships with organizations through a study of Web 2.0 [interactive internet applications]. ${ }^{55}$ Idoughi, Seffah, and Kolski recommend integrating "personae," or perceived personality types and characteristics, into user-design to address challenges in creating software offering highly personalized services. ${ }^{56}$ Pang and Schauder take a community-based approach to systems design, particularly in libraries and museums and encourage system designers to draw on the study of relationships and interaction within different communities as a means to gain insight into more user-centric design methods. ${ }^{57}$

A user-centric focus has extended itself to catalog design ${ }^{58}$ and information-retrieval systems design..$^{59}$ It has been applied as a learning approach to organizational culture within libraries. ${ }^{60}$ Scholarly research within the library is said also to have benefitted because a user-centric focus informs how different types of users interact with information within the library. ${ }^{61}$ Through an analysis of user language, user-centricity is also applied as a means to identify strategies for creating language tools for web searching. ${ }^{62}$ Such studies are representative of the ways a usercentric paradigm proliferates within LIS.

These models and studies highlight the importance of the user perspective and how the user engages with information at various levels. Radical Change Theory (RCT), developed by Eliza Dresang in 1999, goes one step further and adds another element to the user-information interaction: the user's interaction with other users and the response to the interactive applications 
and digital technologies in which information is becoming embedded. This element is mirrored in such applications as Twitter and Foursquare, which allow digital overlays of information to see if there are individuals "near you" also logged on to these networking applications.

The highly complex AR applications call for a highly complex view of human interaction with those applications. Radical Change Theory helps to explicate the characteristics of human expectations and interactions with information in digital formats. Coupled with an examination of AR discourse within LIS literature, RCT helps clarify how people, or users, are approaching the changing information landscape.

\section{RESEARCH APPROACH}

This study focuses on the user-centric paradigm prevalent in LIS, seeking to understand the relationship between the conceptualization of an emerging technology and the role of the user. The research questions guiding this study are the following:

- How is augmented reality (AR) conceptualized in LIS?

- What is the role of the user in relation to AR as it is conceptualized in LIS?

The aim is to understand how a specifically LIS user-centric focus can apply to the conceptualization of AR and its use within libraries and cultural heritage institutions.

The model for this study is Clement and Levine, which examined how pre-1978 dissertations were published and what the concept of copyright was for those dissertations. The unit of sampling in their study was the written message, "defined as a complete statement or series of statements with a distinct start and end." Each message under investigation required author-specified semantic concepts. The researchers then selected recording units, what they describe as "explicit assertions" pertaining to the publication of dissertations. The authors delineated explicit assertions as taking several forms, from a phrase within a sentence to a multipage argument. 63

For the purpose of this study, I investigated written messages contained in the journals and blog posts I chose as well as links to other webpages or blog posts contained in the initial data set. The semantic concept is the term augmented reality. The recording unit is any explicit assertions made regarding augmented reality using the same range of form as Clement and Levine. ${ }^{64}$

In this study, I allied content analysis with Radical Change Theory (RCT). RCT focuses on the characteristics of interactivity, connectivity, and access, which are all dependent on measures of human connections through various forms of media. The characteristics of these principles are as follows:

- Interactivity refers to dynamic, user-initiated, nonlinear, nonsequential, complex information behavior, and representation.

- Connectivity refers to the sense of community or construction of social worlds that emerge from changing perspectives and expanded associations. 
- Access refers to the breaking of long-standing information barriers, bringing entrée to a wide diversity of opinion and opportunity. 65

Content analysis of LIS literature related to AR through the RCT framework allowed me to find connections between the conceptualization of a technology and how the conceptualization functions within a given academic community. During the data analysis, I assessed whether the characteristics of interactivity, connectivity, and access are present in the descriptors of AR. Understanding how AR is brought into the discourse of LIS in LIS literature helps describe the ways an emerging technology is developed as a concept and as a tool through an examination of how researchers and practitioners perceive the need for and use of AR.

Data collected from searches of Google Blogs and the Library, Information Science and Technology Abstracts with Full Text (LISTA) database aided in understanding the conceptualization of AR and the role of the user in relation to the conceptualization. All the searches took place over three months, December 2012 to February 2013, and all searches centered on the search term "augmented reality" (the term was enclosed in quotation marks in the search box).

Through purposeful criterion sampling, all search results including the term "augmented reality" are included in the initial list of data for analysis. I chose the Google Blogs search engine because of its popularity, familiarity, ease of use, and variety of viewpoints. Blogs are an important source of data because they continue to increase in popularity across disciplines, including LIS, and serve as a way for people to communicate with one another and exchange information. ${ }^{66}$ The LISTA database is easy to access; provided free to libraries; familiar to students, faculty, and professionals in the field of LIS; and covers a broad spectrum of general and specialized journals. Together, search results comprise both academic and popular, or mainstream, sources.

\section{Google Blogs}

I first gathered data from searches of Google Blogs. I conducted two separate searches of the search term "augmented reality." The first was in December 2012 and the second was in February 2013. The first search yielded 373 results and the second yielded 376. I used the advanced search function to limit the search to blog postings between June 2012 and December 2012. The second search is limited to June 2012 to February 2013. Blog postings excluded from the final body of data for analysis include foreign-language entries, duplicate items, video-only postings, and advertisements, resulting in a final data set of 300 postings.

\section{Library, Information Science and Technology Abstracts with Full Text (LISTA)}

After completing my search of Google Blogs, I gathered data from LISTA database searches. I searched the database once a month for three months, from December 2012 to February 2013. I divided each monthly search into three search types: first by author-supplied keyword, second by subject terms, and third by all-text, resulting in nine searches. I did this to determine whether the results would differ across each search specification. I then cross-referenced these lists and 
removed duplicate and foreign-language results to compile one complete data set of 160 articles. Recording units from the articles, blog, or social media postings I collected from these searches include explicit assertions concerning AR I then coded. For the purposes of this exploratory study, I developed codes inductively rather than approaching the data with a predetermined set of codes, as inductive codes arise from the interpretation of the coded data. ${ }^{67}$ An example of an assertion in the dataset includes the following, taken from an article in my pilot study:

AR is a very efficient technology for both higher education such as universities and colleges. Students in both schools can improve their knowledge and skills, especially on complex theories or mechanisms of systems or machinery. ${ }^{68}$

I categorized these assertions according to the themes or codes with which they are embedded. For instance, in the assertion above, the notion that AR is efficient and capable of improving or adding to knowledge and skills could be categorized within similar assertions about the value or purpose of AR. After I organized the codes and categories, I determined which, if any, of these codes coincide with the digital age principles of RCT interactivity, connectivity, and access.

I developed 132 codes. A further reduction of codes is not feasible given the myriad ways AR is defined across sources in the data set, which underscores the lack of consensus on just how AR is truly understood. I went through the codes and grouped them according to similarities and overarching themes labeled as categories. The 132 codes make up 14 categories, listed in table 1.

\section{How is AR conceptualized in LIS?}

The LISTA database includes more than 560 journals from LIS and related information-science fields such as communication and museum studies. Of the 77 LISTA sources included in the data set for this study, 46 sources are peer-reviewed; 31 are not. Of those journals not peer-reviewed, all of them focus specifically on issues in the media, technology, education or libraries. Based on my analysis, the categories or overarching themes most prominent in the LISTA data set are "AR as a new direction," "AR as informational," and "AR as an enhancement."

Taken together, these categories suggest AR can deliver information and the user can interact with information through an enhanced experience, which is a new direction in technology. Individually, these categories are loaded with implications based on the codes each category encompasses. The category of AR as a new direction itself includes twenty-five codes. The codes include assertions of "AR as a new normal, providing opportunities" for those willing to implement the technology because of its "potential, versatile" (yet debatable) range of uses from the business sector to education. 
A New Direction

A New World

New Direction

New Normal

Relevant

Unstoppable

Important

Raising Expectations

Popular

Trend

Versatile

Has Potential

Needs Further Development

Under-Utilized

Unfamiliar

Promising

Searching

Opportunity for Leadership

Provides Opportunity

Background

Debatable

Familiar

Skepticism \& Understanding

Entertaining Over Practical

III-defined

Redefined

Valuable

\section{Obtainable}

Access*

Questionable Access

Democratization

Relative Ease of use

Simplicity

Requiring knowledge

Characterized by Empty Descriptors

Amazing

Cool

Exciting

Fun

Unique

Awkward

Unpredictable

Entrancing

Phenomenon

Magic

Evoking Legal Questions

Beginning Litigation

Marketing Disputes

Privacy Concerns
Acting Upon reality

Blurs Line Between Real \& Virtual

Distinction Between Real \& Virtual

Layered Reality

Overlay Worlds

Integrated

Embellishment

Improves Reality

Bringing to Life

Used to Simulate

Unifying

Crossing Boundaries

Intelligent

Transferring Intelligence

Making Meaning

Multimedia Display

Generates Media

Visual as Better than Textual

An Experience

\section{A Modifier}

Catalyst for Change

Changing Network Structure

Eliminates Objects

Potential for Eliminating People

Transformative

Revolutionary

Problem Solver

Restorative

Capable of Injury

Safety

Disruptive

Innovative

Influential

Powerful

\section{Confrontational}

Challenging Perceptions

Challenging

Therapeutic

Utilizes Mobile Devices

Wearable

\section{Informational}

Changing Definitions of Personal Information

Delivering Information

Defining Relevant Information

Helps Gather Information

Presenting Location-Based Information

Speed of Information Delivery

Superimposes Information

Providing Services to User
Conditioning the Environment

Control Environment

Creating Environment

Increases view of the Environment

Contextual

Omnipotent Presence

Used as a Tool

Discovery Tool

Educational Tool

Marketing Tool

Utility for Library Operations

Utility for Library Operations

Library Instruction Aid

Mobile Learning

Reading Aid

Increases Motivation

Promote Libraries

Prompts Action

Impacting Economics

Economic Barriers

Economic Growth

Low Cost

Reducing Costs

Business Model

Retail

Measurable

Niche Market

Gimmick

\section{Progressive}

Eighth Mass Medium

Occurs in Phases

Part of a Continuum

Involving Imagination

Envisioning

Science Fiction

The Future

\section{An Enhancement}

Enhance Communication

Enhance User Experience

Enhance Reality

Enhancing Learning and Training

Enhancing the Library

Enriching

Engaging

Interactivity*

Building Relationships

Collaboration

Connectivity*

Table 1. Codes Grouped by Category.

* Denotes principles of Radical Change Theory 
While the technology still needs development in terms of user awareness of the technology, a clear definition of the technology, and an understanding of its full range of uses, some view it as a trend that raises the bar of technological expectations. When viewed as a growing trend, AR is creating a new world or platform for information delivery.

Furthermore, in the LISTA sources AR is also viewed as informational. This category comprises eight codes, all of which refer to the capability of AR to deliver, gather, define, present, and superimpose information rapidly. In this context for LIS, AR is another format for providing the user with information tailored to specific user needs. The ways AR can provide users with information are nestled in the view of AR as an enhancement.

Within this category, AR is described as an enhancement of reality, communication, experiences, and learning. Under this category there is little AR will not enhance. The enhancement of the user experience is directly tied to the informational quality of AR. This enhancement rests on the engaging interactive qualities of AR fostering relationships and collaboration through the property of connectivity. Under this definition, the digital information AR displays or "creates" is the enhancement of the experience.

Sources in the data set also suggest AR enhances the learning experience through the digital images or objects presented to the user in conjunction with the "original materials." The connection of AR to the Internet and sources therein also gives users the ability to connect and collaborate with one another. The enhanced experiences provided by way of AR foster connections between users as well as librarians and the creators of AR applications themselves. Authors within the data set expect connecting with others and building relationships will make user experiences much richer in terms of how the user interacts with information and in what way information is presented to the user.

The Google Blogs search was not limited to LIS-specific blogs, as the search function is limited in definable search parameters. Of the 300 blog posts in the data set, only four actually include the term library or refer to AR applications within libraries. One blog post alludes to archiving but does not explicitly mention a library setting. These blog postings code for versatility, utility, interactivity, discovery tool, an experience, a library instruction aid, promoting and enhancing the library, access, and providing services to users. While not all of these codes are included in the three dominant categories coding for the LISTA sources, they do reflect the utilitarian quality of AR as a provider of information at its most basic. For example, AR is in one source a versatile tool enhancing aspects of the user's library experience, a view shared with the aforementioned LISTA excerpts, from the ways services are provided for the user to the level of interactivity the patron has with relevant information within the library, such as finding specific book locations or accessing information about the services the library offers. 
Archiving information displayed through AR applications poses a challenge and is a necessary consideration for those interested in archiving information. Truly, AR has the potential to change archiving platforms and access to those platforms. The archiving of information presented via AR is a concern for those implementing AR for a variety of purposes. Presenting even library hours or wayfinding information for a user through AR also raises the question of how information will be accessed, for how long, and in what form it will exist once it is no longer needed, updated, or changed.

The coded data suggests AR is conceptualized as a new development in digital technology worth paying attention to, at least for now, but should also be approached with some caution; users or those looking to implement AR should be careful to understand the functionality and implications of using AR prior to adapting the technology. As reflected in the sources, books and physical spaces are potential areas for AR application and in some cases are already overlaid with AR and are enhancing user experiences. As a whole, the conceptualization of AR is a technology with great potential to change the way users interact with information because of its versatility, mobility, and direct interaction with the user's immediate environment.

\section{What Is the Role of the User in Relation to AR as it is Conceptualized in LIS?}

The user is the foundation of AR, giving the technology its functionality or prompting action. Whether conceptualized as a new direction, an information source or provider, or an enhancement, AR is essentially static if there is no user prompting the AR application to "act." Without action on the user's part, the information stored within AR applications is inert. The goal of AR is to present information in digital form within the context of the user's surroundings, environment, or reality.

Codes describing AR as a new direction, new world, or new normal solidify the idea that AR is a new technological development poised to redefine not only the information landscape but also the ways users interact with technology and information. Furthermore, references to AR as a seemingly unstoppable popular trend point to the perceived usefulness and importance of AR in the life of the user, as it is seen to raise expectations in terms of how users access information. One blog source writes, "You may have heard about augmented reality before. If you haven't, you'll be hearing a lot about it from now on, with the smartphone and tablet revolution now in fullswing." 69 The "revolution" surrounding smartphones and tablets alludes to the increase in their use and sales, making these devices staples in everyday life. This idea is parallel to user expectations in terms of online resources, as many users rely on information accessed through the Internet. ${ }^{70,71,72,73}$ The implication is once AR applications gain more widespread use, the user will come to expect access to a wide range of information through those AR applications.

Because AR is still met with skepticism, and for some is still in need of further development, the technology provides opportunities for librarians and their staff as those implementing and 
providing AR-based services to forge new paths in AR application, becoming users of the technology "behind-the-scenes." The following excerpt from a LISTA source highlights this view:

Technological advances are beginning to fundamentally change the way that library users interact with digital information, and it is therefore essential that librarians become engaged with the relevant technology and leverage their role as teachers in order to help ensure their continued relevance in the lives of clients in the twenty-first century. ${ }^{74}$

Within this statement, librarians are learning and teaching about new technology. Maintaining "relevance in the lives of clients" suggests as the technology grows, implementers of the technology need to understand the technology. As reflected in this excerpt, on the other end is the user (or client) of the AR application after it is created and implemented. The user has the opportunity not only to access and experience information in new ways but also to help build and contribute to the creation and streamlining of the AR application through his or her response to the application's functionality.

The user of AR is also central to the view of AR as informational. In a simplistic way, AR is dormant and incapable of providing, delivering, searching for, superimposing, or really doing much of anything with information without user actions. In most cases with AR, users must have some type of mobile device to prompt what is often described as an AR experience. Information provided via AR applications is unlike the physical format of a book, newspaper, magazine, or other object. These physical objects exist in libraries and the like, residing on shelves and taking up physical space regardless of the location or presence of a user. By contrast, the information embedded within an AR application is only viewable and unlocked when the user prompts action through the viewfinder of a smartphone, tablet, or other mobile device. The technology is described as a catchall or endless repository for interactive information for the user, at the user's fingertips.

Likewise, the conceptualization of AR as any kind of enhancement is also dependent on the user, though this assertion is implicit in many of the coded passages. Without user interaction prompting the AR application to overlay information onto the real environment, AR is incapable of enhancing experiences, libraries, communication, or reality itself. Enhancement, or improvement, suggests something or someone is acted on in a way that is beneficial, intensified, or embedded with a stronger sense of value.

Much like the informational quality of $A R$, without the use of a mobile device handled by the user, AR is dormant and nonexistent, unable to enhance the environment or other aspect of physical life. Without a user within a specific context, there is not much for AR to enhance because it exists as merely a "marker," tucking away the desired information, awaiting a user to come along and point a mobile device in its direction. As blogger David Meyer put it, AR "requires the active participation of the consumer-you do not by default wander around with your phone held out in front of you."75 
This implicit role of the user is buried under language suggesting AR is actually capable of acting on the user and the user's reality, giving AR a sense of agency. For example, in terms of enhancement, while the user is the "activator" of the AR experience, AR is often described as making, creating, challenging, improving, producing, delivering, solving problems, and even bringing some object to life, thus prompting this "enhancement." Such verbs give AR an active quality, as if it is itself alive and present in creating or prompting change. This is best exemplified by the categories of $\mathrm{AR}$ as acting upon reality, $\mathrm{AR}$ as a modifier and $\mathrm{AR}$ as conditioning the environment.

The perceived quality of AR as acting on reality is what often drives the idea of AR is a catalyst for change, conditioning the environment by either controlling the present environment or creating a new one. The transformative characteristic of AR reshapes and redefines the user experience precisely because of the ways AR inserts digital objects into the real-world environment. For this reason, AR is often described through invoking imagination and with words like cool, amazing, fun, and exciting, or other empty descriptors; AR truly enhances user interaction with the surrounding world with what is perceived as a "wow" factor, so much so that codes in this study even reflect legal and economic implications of the technology. But, while AR is a catalyst for change and acts on the environment and reality, those changes and actions are only seen through the viewfinder of a mobile device ultimately in the hands of the user.

\section{RADICAL CHANGE THEORY}

Dresang founded RCT on what she identified as the three digital-age principles of interactivity, connectivity, and access, which describe how "the digital environment has influenced some nondigitized media to take on digital principles." Essentially, Dresang's theory is an attempt to explain information resources and behaviors. Within the digital-age principles, the user takes on the role of initiator. While flexible in allowing user initiation, the digital applications are inert without the user; a range of information is unavailable without user action to put the digital environment into motion. The digital environment within AR, as described by sources in the data set, is an overlay of the digital onto the real world. RCT suggests the "digital environment extends far beyond the digital resources themselves." The extension beyond the digital resources is evident in $\mathrm{AR}$ as it combines the real and physical with the virtual. ${ }^{76}$

Based on these principles and the idea that the digital extends beyond the resources themselves, the conceptualization of AR reflects the characteristics of RCT in explaining information behavior and representations in the AR "environment." Interactivity, connectivity, and access are essential parts of AR. When each principle is examined in conjunction with the coded data, a picture appears of AR as an exemplar of RCT.

Interactivity and connectivity emerged as coded assertions within the data. These codes fall under the category of AR as an enhancement. As stated, AR is expected by many of the voices within my 
data set to influence or enhance almost every aspect of our lives, and part of this enhancement is due to the properties of interactivity and connectivity exhibited by AR.

As defined by Dresang, interactivity refers to dynamic, user-controlled, nonlinear, nonsequential information behavior and representation. ${ }^{77}$ Speaking directly to the idea of user-controlled, nonlinear, and nonsequential information behavior and representation is the sense of agency that AR is expected to give users in terms of how they view and interact with the digital overlays of information.

The control the user has on the AR experience and the information with which he or she comes in contact stems from the functionality of AR often relying on tracking a user's location. Presenting a user with information based on location is not only user-controlled but nonlinear and nonsequential, since the application has no predetermined set of boundaries the way a physical map might have. People do not typically travel through the day in a linear fashion with a predetermined sequence of action. As one blogger notes, AR is "helping to erase that line between your real life and how you interact with the web." 78

AR is further tied to the principle of interactivity as defined within RCT precisely because of its mobility and formatting, namely, because of mobile devices. A source within the LISTA data set includes the following assertion:

The AR paradigm opens innovative interaction facilities to users: human natural familiarity with the physical environment and physical objects defines the basic principles for exchanging data between the virtual and the real world, thus allowing gestures, body language, movement, gaze and physical awareness to trigger events in the AR space. ${ }^{79}$

Gestures, body language, movement, gaze, and physical awareness are all unpredictable actions. For these actions to "trigger events in the AR space," there must certainly be a high degree of nonlinear and nonsequential information behavior and representations taking place; it is highly unlikely user gestures and the like could exist on a linear continuum of action.

Further, within RCT, connectivity refers to the sense of community or construction of social worlds emerging from changing perspectives and expanded associations in the world and in resources. In terms of the coded data in this study, the code of connectivity reflects this idea of creating community and social worlds through the capability of AR to connect users to various forms of social media, to one another, and to various resources. Users make connections through games, location awareness, and applications allowing for the sharing of information from user to user. Social networking figures prominently in AR technology. Users can upload overlays of digital information captured on a smartphone to various social networking sites. Additionally, the ability of AR to overlay digital information onto the real world, and the customizable experiences this creates, aids in connectivity. AR creates a virtual world wherein users can engage with one another across applications; while physically in different places, they can share experiences or 
even simple conversations. Connectivity through AR is possible in all aspects of life as many sources in the data set allude to working, playing, and learning.

To interact and connect with one another, users must have access to the AR space. The principle of access within RCT is defined as the breaking of long-standing information barriers, allowing exposure and access to a wide range of differing perspectives and opportunities. The concept of access (both in terms of what is and is not accessible) does appear in the coded data. Note access and accessibility within this study refer to the opportunity or right to use a system or service, and is not referring to access and accessibility as it is used within discourse pertaining to disabilities.

The use of AR in conjunction with smartphones is a basic way of interpreting access as it relates to RCT and AR. The mobility of smartphones and tablets allows users to access AR across a variety of locations, and each user's smartphone or tablet is uniquely tailored to the user's interests and desires through differing collections of applications and software. Smartphones and tablets are comparatively low-cost options for accessing and sharing access to the Internet and AR applications. Their use is on the rise because they are often much cheaper to obtain than computers. $^{80,81,82}$ The fusion of AR with mobile devices suggests an opportunity for accessing information in real time in any place through these technologies working in tandem with one another. By its very nature, AR offers access to "differing perspectives and opportunities" as it presents the user with information in atypical formats in places and spaces once static, or lacking in digital overlays.

AR is not bounded by physical location; rather, it depends on and varies with your physical location. The idea that users can access AR wherever there is an Internet connection means the only real barrier to accessing AR is the same barrier existing regarding a web connection for the user, something at least one source within the LISTA data set alludes to in terms of the digital divide, cautioning that AR should be used in conjunction with traditional formats of information instead of in lieu of them. For example, libraries should not replace traditional signage with information only embedded within AR applications. However, as more and more organizations, institutions, and businesses use AR and provide users with access rather than relying on the user to conjure his or her own Internet connection, more barriers to AR will fall.

However, it is important to note that not all AR applications actually do require Internet access. Mobile device applications can work off of markers and triggers in the physical environment, not web-based anchors. For example, a cookbook can include a marker next to a recipe that when scanned displays an image of the finished dish. Access to AR applications without a web connection opens a wealth of information to individuals who do not have access to the web. Not all AR applications link to web-based information, and this widens the pool of users engaging with information through those AR applications. Moreover, relative ease of use and low initial cost to create AR applications also allow users to become content creators, as exemplified by an AR application allowing an artist to create virtual graffiti in public spaces. Users are able to display and access information otherwise invisible. 
It is important to note the differing views suggesting AR does and does not require Internet access to function. Such a discrepancy points further to AR as a loosely defined concept. From a technical standpoint, AR does not require an Internet connection, but the Internet does serve as a repository for information, and many see AR as providing a bridge to that information, be it a company wanting to give consumers access to product lines or a library creating an AR application linking to web-based databases and services. In terms of RCT, the principle of access does take into account digital information as able to both provide and inhibit access, as some users may not have access to the often costly hardware allowing access to digitally formatted information. What is important to highlight about the principle of access is the focus on the range of voices and the increased array of digital information available, which, in the case of this study, AR provides. Any object associated in some way with a monetary cost or technical savvy always has the potential to leave some users in the dark.

Interactivity, connectivity, and access are present in the conceptualization of AR within the LIS literature as well as the popular media blogs. The user is central to both RCT and this conceptualization of $\mathrm{AR}$ as a new technology with the potential to change the way users interact with information and with one another. The goal of AR is to present information in digital form within the context of the user's surroundings, environment, or reality. RCT is a theory seeking to understand changes in information behavior and representations, and AR is an exemplar of the myriad changes, or the evolution, of the digital-information environment.

\section{IMPLICATIONS FOR THEORY}

This study has several implications for theory within LIS. These include the extension of RCT or creation of new theories born out of the digital age, the understanding that a user-centric focus is essential to theory within the digital age, and the realization that AR opens new areas of research in what is considered an enhancement of information. While this study sought to test RCT in relation to the conceptualization of $\mathrm{AR}$, it also provides a framework for future studies. The results of this study also suggest AR opens more areas to explore within the field of LIS to create new theories or to add to RCT as a theoretical framework to better understand information behavior and representations in the digital-information environment.

When Dresang initially formulated RCT, she focused on youth information seeking behaviors. ${ }^{83}$ Few scholars have used the theory, but those that have explore education, ${ }^{84}$ literacy, ${ }^{85}$ communication and writing ${ }^{86}$ as related to changing technologies. These previous studies, as well as this study, highlight the importance of this theory in examining the effect of the digitalinformation landscape on information-seeking and user understanding of and reaction to digital information. RCT is viable beyond a focus on youth information seeking and is highly relevant to today's world.

RCT developed to understand how the digital age influences traditional and new media. AR is itself often described as an environment, a digital environment, which is precisely the focus of RCT. If 
AR is in fact a "new normal," as some describe, our information landscape is moving in a direction where interactivity, connectivity, access, and the role of the user are central to any discussion of how information is organized, distributed, formatted, and presented.

Researchers can begin by adapting traditional LIS theories to the digital age. For example, Wilson revised his oft-cited original general model of information-seeking behavior in an attempt to understand the totality of information behavior by linking theory to action and understanding what prompts and hinders the need to search for information. ${ }^{87}$ Researchers can begin to reevaluate the model to determine whether it helps to explain information behavior within the AR environment,or whether aspects of the model can be further developed or revised. Wilson's model's focus on human behavior parallels the focus on human behavior within the AR environment.

Other theories within LIS can also be adapted to the AR environment, such as Erdelez's Information Encountering (IE). Erdelez's theory focuses on a "memorable experience of unexpected discovery of useful or interesting information" situated within three elements: characteristics of the information user, characteristics of the information environment, and characteristics of the encountered information. Erdelez further describes categories of information users: superencounterers, encounterers, occasional encounterers, and nonencounterers. While Erdelez has since taken the web and the Internet into account as information environments, this theory could further be remodeled to include the AR environment. ${ }^{88}$

Wilson's model and Erdelez's theory are just two examples of theories within LIS lending themselves to further exploration of the user of AR within LIS. Bates' model of information search and retrieval, known as berrypicking, which centers on the changing nature of the search query through the search process, can also be amended to include information search and retrieval within the AR environment. ${ }^{89}$ Bates' model suggests as users seek and find information, the information search shifts from source to source. The berrypicking model can also be updated or expounded in response to AR because of AR's multidimensional display of information-a relatively new phenomenon for the average user-to understand whether the same shift in information queries occurs and what new paths to information users are taking within the AR environment.

This study suggests a user-centric focus is essential to any theories in LIS developed within or extended to the digital age. The user is vital to making AR technology functional, as demonstrated in the conceptualization of AR in this study. The personalization, individualization, and mobility of digital technology like AR suggest theories related to information behavior within this environment must account for user interaction. Information is no longer contained within static formats. Geotagging or geospatial awareness and social networking are prime examples of the reliance of digital technology on user interaction. Without addressing the role of the user in the 
functionality of digital technology in any context, theoretical frameworks attempting to address information seeking and behavior in the digital age will be limited.

Additionally, should AR prove to be a new direction in accessing, organizing, delivering, and obtaining information, it further opens new areas of theoretical research. Since AR is considered an enhancement of the information experience, it is incumbent on researchers to determine just how "enhancement" is defined in the context of AR and how that translates to the user experience. Researchers can strive to apply and understand the concept of an enhancement in relation not only to the enhancement of information but also to the experience of accessing, organizing, delivering, and obtaining information. The digital-age principles outlined by Dresang in RCT are just one example of how to understand the impact of the digital age on the user's interaction with information and in what ways the digital age creates enhancements.

By itself, the study of AR technology raises more questions than it answers. The study of AR technology could lead to more diverse theoretical frameworks seeking to answer not only practical questions but also those more philosophical in nature, working toward an understanding of how the digital-information environment influences everyday life as it evolves and changes at a rapid pace.

\section{IMPLICATIONS FOR PRACTICE}

This study can inform several aspects of practice. I expound on three possibilities: the clear definition of technologies like AR to create an awareness and understanding of those technologies, development of best practices, and the need for a focus on user collaboration in the design and functionality of AR and similar technologies. The implications for practice concern both the user and the provider of information services.

This study provides perspective, or a starting point, from which the field of LIS can begin to analyze the use and implementation of AR technology. By taking a step back to understand the current conceptualization of AR, practitioners within LIS can begin to seek consensus, identify best practices, maintain an awareness of how the technology is used and think realistically about what factors contribute to successful implementation of the technology in a given institution. As identified in the study, AR is seen as a new direction. It is important for those within the field to understand this perspective and to go on to identify what a new direction in information gathering, organization, and seeking implies for the field as a whole and for users.

As a field, LIS can begin to have a broader discussion on what exactly AR can provide and how it can benefit user services. Such a discussion can help practitioners make sense of how this technology can work with traditional sources of information. AR can be integrated with the traditional rather than act as a replacement for the traditional. This broader discussion can lead to a consensus on how best to define AR as a tool and concept. Within this study, it is evident AR is described in myriad ways, so it is important to reflect on those descriptions, understand what the issues are surrounding the technology, and collaboratively seek and identify best practices. 
Furthermore, by identifying best practices, practitioners can begin to pinpoint what applications of AR are successful within an institution and for users, and why those applications are successful for specific purposes. In doing so, practitioners can build AR applications around the needs and mission of the institution rather than simply flock to use a new technology. It is therefore critical for practitioners to think realistically about AR implementation. Adopting such a technology will only be beneficial once practitioners in the library understand its full impact. Experience with technology and programming, knowledge of AR functionality, versatility, and cost are important factors to consider when contemplating how an institution can benefit from AR, if at all.

Similarly, publishers are using AR to supplement traditional printed books. Educators are using AR books in the classroom and supplementing traditional course instruction with these books. Such books allow for 3D rendering of models for study, such as planets, molecular structures, and various other objects. Those within LIS have a strong connection to the field of education, and AR books may become a part of the library collection as they become more popular among educators. Practitioners in LIS through collaboration with educators will then need to be aware of these books, their functionality, and how to help users access the content lying dormant until "activated" by a smartphone or tablet. This raises the question as to whether smartphones, tablets or other devices that can scan the environment will become commonplace in the library to provide full access to users.

User collaboration also becomes central to understanding the implications of AR on practice. User collaboration in design is important because AR technology is largely dependent on user context. As the data suggests, AR is considered an enhancement-of the environment, of information, and of the user experience. Prior to implementation, it is critical to understand how AR enhances the user experience and what the perception is among users. User surveys can lead to tailored AR applications for a given library or cultural institution community should there be a need or desire for AR applications identified among users. Coupled with the idea of user collaboration in design is also the need to reevaluate the physical spaces of libraries and similar institutions. Because AR creates an overlay of digital information on the physical environment, it will be necessary for practitioners to identify what areas of the library or institution lend themselves to digital overlays, what types of information users are accessing through AR applications, and whether the library space is configured to allow for navigating space via AR.

Practitioners can also begin to survey the role of RCT in understanding user information-seeking behavior. By acknowledging this theory as an outline of our digital-information environment, practitioners can be mindful of user expectations and behaviors as they differ from traditional information representations and methods of information retrieval. As AR creates an environment or experience for the user, it is important for practitioners within the field to understand how this technology is moving forward and what effect it has on the sea change occurring in user acquisition of information. RCT is a framework providing practitioners the lens through which to make sense of the sea change and predict what might be on the horizon. 


\section{LIMITATIONS AND FUTURE APPLICATION}

This study is just one step in the process of understanding how new technology is conceptualized and what effect that conceptualization has on implementation. Should AR continue to grow in popularity, this study can serve as a model for future research seeking to understand concepts misinterpreted, misunderstood, or undergoing concrete development. Utilizing the explicit assertion as a unit of analysis coupled with RCT can aid in investigations of other digital technologies, both in terms of implementation and end use.

The data set and the time period during which the searches of the data set took place in this study highlight two of the study's limitations. Further studies can focus on a wider range of sources not limited to one database or blog search type and extend over a longer period of time. These limitations have potentially excluded other voices, perspectives, and definitions of AR, and the time element may exclude new applications or uses of AR currently being implemented.

Limitations in data analysis also exist. Content analysis is one of many research methods researchers can employ to explore this topic. Ethnographic research and user interviews can lead to a deeper understanding of how users perceive AR and information-seeking or behavior within the AR environment. Such qualitative studies can provide insight to the role of the user lacking in this study. Moreover, this researcher's own admitted bias against the steadfast use of digital technologies prior to in-depth understanding is what prompted the qualitative inquiry guiding the study. Quantitative methods can also be used to track the popularity or perceptions of AR through close-ended questionnaires or surveys of both users and practitioners in the field of LIS. Citation tracking could further reveal in what subfields of LIS the conversation surrounding AR is taking place, and may also uncover whether any one researcher or group of researchers is leading the conversation.

Future studies can examine and expand on the results of this study. Rather than focusing on conceptualization only, researchers can study which professional fields dominate the conversation surrounding AR and what areas of popular culture dominate the conversation or influence understanding of AR. Similarly, other studies can address the specificity of each source making explicit assertions about this kind of technology. While qualitative in nature, the study is limited because it does not examine quantitative changes in the number of articles or blog posts alluding to AR over an extended period of time. Such studies might unravel why AR is progressing as it is, and may identify potential problems or differences in the influence of these perspectives on the use of AR.

The study of AR also widens the spectrum of user studies. Augmented reality open a whole new area of user interaction with information extending beyond the screen. With the advent of products like Google Glass and applications overlaying digital information at the click of a button in an endless array of contexts and environments, AR brings information-seeking further into a world of instability and unpredictability. The complex nature of individual people is now being coupled with a highly individualized complex technology. 
The functionality of AR prompts the need for archival studies related to this technology. The mobile aspect of AR, the highly personalized content and the intangible quality of the information stored within AR applications highlights the need for an examination of how such information can actually exist within an archive and be made accessible, or whether such information even should exist within an archive. Such a question for those within LIS also suggests the need for a realistic perspective on technology like AR-the next step, or reaction to such technology, is often unrecognizable and unidentifiable until the concept itself is dissected and each part is interpreted and understood.

\section{CONCLUSION}

In this study, I used content analysis to explore the conceptualization of AR technology within the field of LIS. The model for this study is the work of Clement and Levine and their use of the explicit assertion as a unit of analysis. ${ }^{90}$ I coded and examined explicit assertions pertaining to AR in LIS literature and Google Blogs to determine how the concept of AR is understood. Analysis shows AR is most prominently conceptualized as a new direction in technology and media consumption acting on reality and as enhancing reality and interaction with information.

AR is basically a technology allowing for digital information to be superimposed on the real world. But beyond that, it is a technology changing the way users interact with information, and it has the potential to continue changing how we literally see information. The data set suggests those within LIS conceptualize AR as a new development in digital technology worth paying attention to, at least for now, but should also be approached with some caution to be fully understood prior to implementation in case its popularity and growth is fleeting. As reflected in the data set, books and physical spaces are potential areas for AR application, and in some cases are already overlaid with AR and enhancing user experiences. As a whole, AR is conceptualized as a technology with great potential to change the way users interact with information because of its versatility, mobility, and direct interaction with the user's immediate environment.

Within this conceptualization, the user is central to igniting the functionality of AR. Whether conceptualized as a new direction, an information source or provider, or an enhancement, AR is essentially static if there is no user prompting the AR application to "act." The goal of AR is to present information in digital form within the context of the user's surroundings, environment, or reality. As a field dedicated to user services in regard to information-seeking, it is imperative to understand the potential impact this technology has had or will have on everyday life.

RCT is a theoretical framework aiding in the exploration of the potential impact of AR. Born out of a desire to understand the influence of the digital age on the traditional or "analog" media with which we engage, RCT is one of few theories resting entirely on the characteristics driving our digital-information environment, outlined specifically as interactivity, connectivity, and access. Utilizing this theory as a lens for future research regarding digital information is a natural next step in theory exploration and development. 
Together, AR and RCT accentuate the evolution of how we consume and display information. From storytelling to printed pages to electronic devices, our engagement with information will never be the same again. As we move forward, it is important to continue to ask new questions, seek new explanations, and try to formulate the most appropriate answers for the contexts in which we all deal with information, be it gathering, organizing, seeking, or understanding. This study is one piece in a puzzle, and it prompts more questions than it provides answers. AR can and should be studied from every aspect of the field of LIS, if it is in fact a new direction toward our new normal.

\section{REFERENCES}

1. Nathan Crilly, “The Design Stance in User-System Interaction,” Design Issues 27, no. 4 (2011): 16-29.

2. Pelle Ehn, "The End of the User-The Computer as a Thing," in End-User Development, ed. Y. Dittrich, M. Burnett, A. Morch and D. Redmiles (Berlin, Germany: Springer, 2009), 8-8.

3. Daniel Fallman, "The New Good: Exploring the Potential of Philosophy of Technology to Contribute to Human-Computer Interaction." Paper presented at the SIGCHI Conference on Human Factors in Computing Systems, Vancouver, British Columbia, May 2011).

4. Bruce M. Hanington, "Relevant and Rigorous: Human-Centered Research and Design Education," Design Issues 26, no. 3 (2010): 18-26.

5. Manuel Imaz and David Benyon, Designing with Blends: Conceptual Foundations of HumanComputer Interaction and Software Engineering (Cambridge, MA: MIT Press, 2007).

6. Laura Manzari and Jeremiah Trinidad-Christensen, "User-Centered Design of a Web Site for Library and Information Science Students: Heuristic Evaluation and Usability Testing," Information Technology \& Libraries 25, no. 3 (2006): 163-69.

7. Yoram Moses and Marcia K. Shamo, "A Knowledge-Based Treatment of Human-Automation Systems," (2013), http://arxiv.org/abs/1307.2191.

8. Marc Steen, "Human-Centered Design as a Fragile Encounter," Design Issues 28, no. 1 (2012): 72-80.

9. Ronald T. Azuma, "A Survey of Augmented Reality," Presence: Teleoperators and Virtual Environments 6, no. 4 (1997): 355.

10. Antti Aaltonen and Juha Lehikoinen, "Exploring Augmented Reality Visualizations," Proceedings of the AVI '06: Proceedings of the Working Conference on Advanced Visual Interfaces (2006): 453-56, http://portal.acm.org/citation.cfm?id=1133357. 
11. Peter Anders, “Designing Mixed Reality: Perception, Projects and Practice,” Technoetic Arts: $A$ Journal of Speculative Research 6, no. 1 (2008): 19-29, http://dx.doi.org/10.1386/tear.6.1.19_1.

12. Blair MacIntyre, Jay David Bolter, Emmanuel Moreno, and Brendan Hanigan, “Augmented Reality as a New Media Experience," Proceedings of the IEEE and ACM International Symposium on Augmented Reality (New York, New York: 2001), 197-206, http://dx.doi.org/10.1109/ISAR.2001.970538.

13. Aaltonen and Lehikoinen, "Exploring Augmented Reality Visualizations."

14. Benjamin Avery et al., "Evaluation of User Satisfaction and Learnability For Outdoor Augmented Reality Gaming" User Interfaces 2006: Proceedings of the Seventh Australasian User Interface Conference-Volume 50 (Darlinghurst, Australia: Australian Computer Society, 2006), 17-24.

15. Oliver Bimber, L. Miguel Encarnacao, and Dieter Schmalstieg, "The Virtual Showcase as a New Platform for Augmented Reality Digital Storytelling" Proceedings of the EGVE '03: Proceedings of the Workshop on Virtual Environments (New York: ACM, 2003), 87-95, http://portal.acm.org/citation.cfm?id=769964.

16. Push Singh, Barbara Barry and H. Liu, "Teaching Machines About Everyday Life," BT Technology Journal 22, no. 4 (2004): 211-26.

17. Alan M. Turing, “Computing Machinery and Intelligence,” Creative Computing 6, no. 1 (1950): 44-53.

18. Chih-Ming Chen and Yen-Nung Tsai, "Interactive Augmented Reality System for Enhancing Library Instruction in Elementary Schools," Computers and Education 59, no. 2 (2012): 63852.

19. David Chen et al., "Mobile Augmented Reality for Books on a Shelf." Paper presented at 2011 IEEE International Conference on Multimedia and Expo (ICME), Barcelona, Spain, July 2011, http://dx.doi.org/10.1109/ICME.2011.6012171.

20. Giovanni Saggio and Davide Borra, "Augmented Reality for Restoration/Reconstruction of Artefacts with Artistic or Historical Value" (informally published manuscript, University of Rome, Italy, 2012), http://tainguyenso.vnu.edu.vn/jspui/handle/123456789/29953.

21. Andre Walsh, "QR Codes-Using Mobile Phones to Deliver Library Instruction and Help at the Point of Need," Journal of Information Literacy 4, no. 1 (2010): 55-63.

22. Azuma, "A Survey of Augmented Reality." 
23. Telmo Zarraonandia et al., "Augmented Lectures around the Corner?" British Journal of Educational Technology 42, no. 4 (2011): E76-E78.

24. Mark Billinghurst and Andreas Duenser, "Augmented Reality in the Classroom," Computer 45, no. 7 (2012): 56-63.

25. Angela Di Serio, Maria Blanca Ibanez, and Carlos Delgado Kloos, "Impact of an Augmented Reality System on Students' Motivation for a Visual Art Course," Computers and Education 68 (2013): 586-96.

26. Liv Valmestad, "Q(a)r(t) Code Public Art Project: A Convergence of Media and Mobile Technology," Art Documentation: Journal of the Art Libraries Society of North America 30, no. 2 (2011): 70-73.

27. Claudio Kirner et al., "Design of a Cognitive Artifact Based on Augmented Reality to Support Multiple Learning Approaches," Proceedings of World Conference on Educational Multimedia, Hypermedia and Telecommunications (Denver, CO: June 2006).

28. Deborah Lee, "The 2011 Horizon Report: Emerging Technologies," Mississippi Libraries 75, no. 1 (2012): 7-8.

29. George Margetis et al., "Augmented Interaction with Physical Books in an Ambient Intelligence Learning Environment," Multimedia Tools and Applications 67, no. 2 (2013): 473-95, http://dx.doi.org/10.1007/s11042-011-0976-x.

30. Stefaan Ternier and Fred De Vries, "Mobile Augmented Reality in Higher Education." Paper presented at the Learning in Context ' 12 Workshop, Brussels, Belgium, March 2012, http://hdl.handle.net/1820/4219.

31. Bimber, Encarnacao, and Schmalstieg, "The Virtual Showcase as a New Platform for Augmented Reality Digital Storytelling."

32. Alisa Barry et al., "Augmented Reality in a Public Space: The Natural History Museum, London," Computer, 45, no. 7 (2012): 42-47, http://doi.ieeecomputersociety.org/10.1109/MC.2012.106.

33. David Marimon et al., "Mobiar: Tourist Experiences Through Mobile Augmented Reality." Paper presented at the Networked and Electronic Media Summit, Barcelona, Spain, 2012.

34. Ann Morrison et al., "Collaborative Use of Mobile Augmented Reality with Paper Maps," Computers and Graphics 35, no. 4 (2011): 789-99.

35. Yetao Huang et al., "Iterative Design of Augmented Reality Device in Yuanmingyuan for Public Use," Vrcai '11: Proceedings of the 10th International Conference on Virtual Reality Continuum 
and its Applications in Industry, Hong Kong, 2011 (New York: ACM, 2011), http://dx.doi.org/10.1145/2087756.2087847.

36. Azuma, "A Survey of Augmented Reality."

37. Selim Balcisoy and Daniel Thalmann, "Interaction between Real and Virtual Humans in Augmented Reality." Paper presented at Computer Animation, Geneva, Switzerland, 1997, http://portal.acm.org/citation.cfm?id=791510.

38. Enylton Machado Coelho, Blair MacIntyre, and Simon J. Julier, "Supporting Interaction in Augmented Reality in the Presence of Uncertain Spatial Knowledge." Paper presented at the Eighteenth Annual ACM Symposium on User Interface Software and Technology, Seattle, WA, October 23-27, 2005, http://citeseerx.ist.psu.edu/viewdoc/summary?doi=10.1.1.91.4041.

39. Brian X. Chen, "If You're Not Seeing Data, You're Not Seeing," Wired (blog), August 25, 2009, http://www.wired.com/gadgetlab/2009/08/augmented-reality/.

40. Isabel Pedersen, "A Semiotics of Human Actions for Wearable Augmented Reality Interfaces," Semiotica 155, no. 1-4 (2005): 183-200.

41. Ibid.

42. Balcisoy and Thalmann, "Interaction Between Real and Virtual Humans in Augmented Reality."

43. Ray Kurzweil, “Robots 'R' Us,” Popular Science 269, no. 3 (2006): 54-57.

44. Chen, "If You're Not Seeing Data, You're Not Seeing."

45. Avery et al., "Evaluation of User Satisfaction and Learnability For Outdoor Augmented Reality Gaming."

46. Gerhard Reitmayr and Dieter Schmalstieg, "Location Based Applications for Mobile Augmented Reality" Paper presented at the Fourth Australian User Interface Conference on User Interfaces, Adelaide, Austrialia, 2003.

47. Coelho, MacIntyre and Julier, "Supporting Interaction in Augmented Reality in the Presence of Uncertain Spatial Knowledge."

48. Carol C. Kuhlthau, Seeking Meaning: A Process Approach to Library and Information Services (Westport, CT: Libraries Unlimited, 2004).

49. Crystal Fulton, "Chatman's Life in the Round," in Theories of Information Behavior, ed. Karen E. Fisher, Sanda Erdelez, and Lynne McKechnie (Medford, NJ: Information Today, 2009), 79-82.

50. Constance A. Mellon, “Library Anxiety: A Grounded Theory and Its Development," College \& Research Libraries 47 (1986), 160-65. 
51. Donald O. Case, Looking for Information: A Survey of Research on Information Seeking, Needs and Behavior (New York: Academic Press, 2008).

52. Leanne Bowler et al., "Issues in User-Centered Design in US," Library Trends 59, no. 4 (2011): 721-52.

53. Ibid.

54. Heather L. O'Brien and Elaine G. Toms, “What is User Engagement? A Conceptual Framework for Defining User Engagement with Technology," Journal of the American Society For Information Science \& Technology 59, no. 6 (2008): 938-55.

55. Liu Shu, “Engaging Users: The Future of Academic Library Web Sites," College \& Research Libraries 69, no. 1 (2008): 6-27.

56. Djilali Idoughi, Ahmed Seffah, and Christophe Kolski, "Adding User Experience into the Interactive Service Design Loop: A Persona-Based Approach," Behaviour \& Information Technology 31, no. 3 (2012): 287-303.

57. Natalie Pang and Don Schauder, "The Culture of Information Systems in Knowledge-Creating Contexts: The Role of User-Centred Design," Informing Science 10 (January 2007): 203-35.

58. Michelle L. Young, Annette Bailey, and Leslie O’Brien, “Designing a User-Centric Catalog Interface: A Discussion of the Implementation Process for Virginia Tech's Integrated Library System," Virginia Libraries 53, no. 4 (2007): 11-15.

59. Shawn R. Wolfe and Yi Zhang, "User-Centric Multi-Criteria Information Retrieval” (paper presented at the 32nd International ACM SIGIR Conference on Research and Development in Information Retrieval, Boston, July 19-23, 2009).

60. Mary M. Somerville and Mary Nino, "Collaborative Co-Design: A User-Centric Approach for Advancement of Organizational Learning," Performance Measurement \& Metrics 8, no. 3 (2007): 180-88.

61. Tamar Sadeh, "User-Centric Solutions for Scholarly Research in the Library," Liber Quarterly: The Journal of European Research Libraries 17, no. 1-4 (2007): 253-68.

62. Bettina Berendt and Anett Kralisch, "A User-Centric Approach to Identifying Best Deployment Strategies for Language Tools: The Impact of Content and Access Language on Web User Behaviour and Attitudes," Information Retrieval 12, no. 3 (2009): 380-99.

63. Gail Clement and Melissa Levine, "Copyright and Publication Status of Pre-1978 Dissertations: A Content Analysis Approach," portal: Libraries and the Academy 11, no. 3 (2011): 813-29, http://dx.doi.org/10.1353/pla.2011.0032.

64. Ibid. 
65. Eliza T. Dresang, "Radical Change," in Theories of Information Behavior, ed. Karen E. Fisher, Sanda Erdelez, and Lynne McKechnie (Medford, NJ: Information Today, 2009), 298-302.

66. Grace M. Jackson-Brown, "Content Analysis Study of Librarian Blogs: Professional Development and Other Uses," First Monday 18, no. 2 (2013): 2.

67 Dahlia K. Remler and Gregg G. Van Ryzin, Research Methods in Practice: Strategies for Description and Causation (Los Angeles: Sage, 2011).

68. Kangdon Lee, "Augmented Reality in Education and Training," Techtrends: Linking Research and Practice To Improve Learning 56, no. 2 (2012): 13-21.

69. YFS Magazine, "Interview: Gravity Jack CEO, Luke Richey Talks Industry Leadership, Augmented Reality and Why Cash Isn't King," Yfsmagazine.com (blog), December 19, 2012, http://yfsentrepreneur.com/2012/12/19/interview-gravity-jack-ceo-luke-richey-talksindustry-leadership-augmented-reality-and-why-cash-isnt-king/ .

70. Carol Pitts Diedrichs, "Discovery and Delivery: Making it Work for Users," Serials Librarian 56, no. 1-4 (2009): 79-93.

71. Baker Evans, "The Ubiquity of Mobile Devices in Universities-Usage and Expectations," Serials 24 (2011): S11-S16.

72. Andrew J. Flanagin and Miriam J. Metzger, "Perceptions of Internet Information Credibility," Journalism and Mass Communication Quarterly 77, no. 3 (2000): 515-40.

73. Ronald M. Solorzano, "Adding Value at the Desk: How Technology and User Expectations are Changing Reference Work," Reference Librarian 54, no. 2 (2013): 89-102, http://dx.doi.org/10.1080/02763877.2013.755398.

74. Robin Canuel, Chad Crichton, and Maria Savova, "Tablets as Powerful Tools for University Research," Library Technology Reports 48, no. 8 (2012): 35-41.

75. David Meyer, "Telefonica Bets on Augmented Reality with Aurasma Tie-In," Gigaom (blog), September 17, 2012, http://gigaom.com/2012/09/17/telefonica-bets-on-augmented-realitywith-aurasma-tie-in.

76. Eliza T. Dresang, "The Information-Seeking Behavior of Youth in the Digital Environment," Library Trends 54, no. 2 (2005): 178-96.

77. Ibid.

78. Dave Rodgerson, "Experiments in Augmented Reality Hint at its Potential for Retailers," Future of Retail Alliance (blog), October 5, 2012, http://www.joinfora.com/experiments-inaugmented-reality-hint-at-its-potential-for-retailers/. 
79. Wolfgang Narzt et al., "Augmented Reality Navigation Systems," Universal Access in the Information Society 4, no. 3 (2005): 177-87.

80. Mito Akiyoshi and Hiroshi Ono, "The Diffusion of Mobile Internet in Japan," Information Society 24, no. 5 (2008): 292-303, http://dx.doi.org/10.1080/01972240802356067.

81. Jeffrey James, "Institutional and Societal Innovations in Information Technology for Developing Countries," Information Development 28, no. 3 (2012): 183-88.

82. Andromeda Yelton, "Dispatches from the Field. Bridging the Digital Gap," American Libraries 43, no. 1/2 (2012): 30, http://www.americanlibrariesmagazine.org/article/bridging-digitaldivide-mobile-services.

83. Dresang, “The Information-Seeking Behavior of Youth in the Digital Environment.”

84. Marta J. Abele, "Responses to Radical Change: Children's Books by Preservice Teachers" (doctoral dissertation, Capella University, Minneapolis, Minnesota, 2003).

85. Jacqueline N. Glasgow, "Radical Change in Young Adult Literature Informs the Multigenre Paper," The English Journal 92, no. 2 (2002): 41-51, http://www.jstor.org/stable/822225.

86. Sylvia Pantaleo, "Readers and Writers as Intertexts: Exploring the Intertextualities in Student Writing," Australian Journal Of Language and Literacy 29, no. 2 (2006): 163-81, http://search.informit.com.au/documentSummary;dn=157093987891049;res=IELHSS.

87. Tom D. Wilson, "Information Behavior: An Interdisciplinary Perspective," Information Processing \& Management 33, no. 4 (1997): 551-72.

88. Sanda Erdelez, "Information Encountering: It's More than Just Bumping into Information," Bulletin of the American Society for Information Science \& Technology 25, no. 3 (1999): 25-29, http://www.asis.org/Bulletin/Feb-99/erdelez.html.

89. Marcia J. Bates, "The Design of Browsing and Berrypicking Techniques for the Online Search Interface," Online Review 13, no. 5 (1989): 407-24.

90. Clement and Levine, "Copyright and Publication Status of Pre-1978 Dissertations.” 